Kirchgessner, M., Munz, W. \& Oelschläger, W. (1960). Arch. Tieremähr. xo, x.

Marston, H. R. (1970). Br. F. Nutr. 24, 6r5.

Mills, C. F. (editor) (1970). Trace Element Metabolism in Animals. Edinburgh: Livingstone.

Mills, C. F., Dalgarno, A. C., Williams, R. B. \& Quarterman, J. (I967). Br. F. Nutr, 2r, 75 r.

National Research Council (1960). Publs natn. Res. Coun., Wash. no. 827.

National Research Council (1964). Publs natn. Res, Coun., Wash. no. I I92.

National Research Council (1966). Publs natn. Res. Coun., Wash. no. 1349.

National Research Council (1968a). Publs natn, Res. Coun., Wash. no. I694.

National Research Council (1968b). Publs natn. Res. Coun., Wash. no. I693.

National Research Council (1970). Publs natn. Res. Coun., Wash. no. I $37,4^{\text {th }}$ ed.

Oberleas, D. \& Prasad, A. S. (1970). In Trace Element Metabolism in Animals p. I70 [C. F. Mills, editor]. Edinburgh: Livingstone.

Ott, E. A., Smith, W. H., Stob, M., Parker, H. E., Harrington, R. B. \& Beeson, W. M. (1965). Y. Nutr. 87,459 .

Plumlee, M. P., Thrasher, D. M., Beeson, W. M., Andrews, F. N. \& Parker, H. E. (1956). F. Anim. Sci. I5, 352 .

Scott, R. O. (1970). In Trace Element Metabolism in Animals p. 497. [C. F. Mills, editor]. Edinburgh: Livingstone.

Smith, B. S. W., Field, A. C. \& Suttle, N. F. (1968). F. comp. Path. Ther. 78, 449.

Swenerton, H. \& Hurley, L. S., (1968). F. Nutr. 95, 8.

Underwood, E. J. (1962). Trace elements in Htman and Animal Nutrition and ed. New York and London: Academic Press.

Underwood, E. J. (1966). The Mineral Nutrition of Livestock. Farnham Royal: Commonwealth Agricultural Bureaux.

\title{
Genetic variation in mineral metabolism of ruminants
}

By Gerald Wiener, Agricultural Research Council, Animal Breeding Research Organisation, Edinburgh EH9 $37 Q$ and A. C. FIELD, Moredun Research Institute, Edinburgh $\mathrm{EH}_{\mathbf{1}} 77^{\mathscr{f} H}$

The occurrence of disorders of mineral metabolism in cattle and sheep, for example hypocalcaemia, hypomagnesaemia or swayback, suggests that some individuals are unable to meet their mineral requirements. The question arises whether such differences among individuals are inherited and can be affected by a breeding policy.

The incidences of most of the metabolic disorders are low and sporadic, even though costly. Generally, under these circumstances little progress can be expected in reducing the incidence of these metabolic disorders in future generations by removing, or allowing nature to remove, only the clinically affected animals from the breeding population. Even such little change as might be expected from natural selection is counteracted by normal husbandry and veterinary practices which preserve deficient individuals by rescuing them from the consequences of disorder or by preventing its manifestation (an example relating to swayback is discussed by Wiener (I97I)).

Genetic progress in reducing metabolic disorders is most likely to be made if the underlying biochemical variation is understood, is measurable in apparently healthy animals and is inherited. More urgency is given to finding answers to the appropriate questions if the disorders are expected to increase in frequency as higher 
production and intensive husbandry systems impose additional stresses on the animals or, conversely, as ruminants are expected to make increasing use of the extensive, more 'deficient' areas of the world, and of plant and industrial by-products.

Suboptimal performance has also been associated with mineral deficiency or imbalances (Underwood, rg66) and reports in the literature are not uncommon of favourable responses to dietary additions of, for example, cobalt, copper or selenium where no clinical symptoms of deficiency were detected. If genetic variation is demonstrated at the level of clinical disorder, it must also be sought at other points in the scale from disease at one end to optimum performance at the other.

This paper reviews the evidence to date for genetic variation in disorders of mineral metabolism, and in the mineral concentrations in blood, milk, excreta and tissues of sheep and cattle. Some of the results from cattle blood are presented for the first time.

\section{Disorders associated with mineral metabolism}

Swayback. Large differences among breeds and among sire progeny groups in the incidence of swayback in lambs were reported by Wiener (1966). The flocks concerned had been self-contained for many years and the different breeds or sireprogeny groups had been born together and treated alike. All sheep were at grass throughout the year. In one flock (subsequently referred to as flock A) the breeds were Scottish Blackface, Cheviot and Welsh Mountain, and the crosses among these. In another flock (B), Blackface ewes had been mated to rams of the Border Leicester, Clun Forest, Dorset Horn, Finnish Landrace and Merino breeds, and the female offspring of these matings had been further crossed with rams of the Oxford Down, Soay and Southdown breeds. A third flock (C) provided a comparison between offspring of Border Leicester and Wiltshire rams. The breed incidences in swayback ranged from 0 to $40 \%$ of the lambs born and the differences among sire groups were similar. Since the breeds also differed markedly in body size, it appeared plausible that the variation in swayback incidence might be related primarily to variation in size and hence indirectly to intake of nutrients. Re-analysis of the data after adjustment for the effects of weight of ewe and of lamb, however, confirmed the statistical significance of the genetic variation in swayback incidence (Wiener \& Sampford I969).

Suttle \& Field ( 1969 ) have reported marked differences in the responses, including the induction of swayback, of groups of sheep derived from different flocks following prolonged experimental depletion of $\mathrm{Cu}$.

Copper poisoning. Prophylactic subcutaneous injections of $50 \mathrm{mg}$ of a coppercalcium complex of EDTA were given to the ewes in flock $A$ in the years following the outbreak of swayback of 1964 . Seventeen sheep ( $1 \cdot 04 \%$ of those injected over a 5-year period) died shortly after the injection and although the risks of death were found to be strongly associated with the dose given per unit live weight of sheep there was also a significant breed difference in mortality (Wiener \& Macleod, 1970). It is interesting in this context that in a discussion on $\mathrm{Cu}$ toxicity, Marston (I950) 
claimed that, under experimental conditions, British breeds of sheep usually succumb to the first haemolytic crisis whereas Merino sheep may survive two or three such crises.

Milk fever. Differences in the breed incidence of this disorder in cattle have been acknowledged for a long time and were shown in the survey by Leech, Davis, Macrae \& Withers (I960). Data from various other sources were summarized by Meyer (I968) to give incidences of $13.8 \%$ for Jersey, $8.6 \%$ for Guernsey, $5.5 \%$ for Ayrshire and $4.8 \%$ for Holstein. It must be recognized, however, that these different breeds are not normally kept in the same herds and that the breed differences may be confounded with environmental and management differences. Confidence in a genetic effect is, therefore, strengthened by the observation of D. Gibson (unpublished data) that Jerseys had an average incidence of milk fever over five lactations of $18.7 \%$ compared with $8.0 \%$ for Friesian and $3.5 \%$ for Ayrshire in a herd belonging to the Animal Breeding Research Organisation where all three breeds were born and kept together.

J. L. Read (unpublished data) has also recorded a breed difference in losses thought to be due to hypocalcaemia in lactating Swaledale and Blackface ewes run together as a single grassland flock by the Animal Breeding Research Organisation.

Grass tetany. The survey of Leech et al. (1960) also showed a breed difference for this source of loss in cattle. The reservations, stated above, about attributing the differences to breed alone apply also to this evidence.

Other disorders. Goitre in lambs has been generally attributed to iodine deficiency or goitrogenic factors but Rac, Hill, Pain \& Mulhearn (1968) and Mayo \& Mulhearn (r969) have described a similar condition duc to the action of a recessive gene. Complex biochemical analysis of this form of congenital goitre revealed not merely the disordered biosynthesis of thyroid hormones (Falconer, ${ }^{1965}$ ) but that sheep heterozygous for the gene, and hence clinically normal, showed, on average, elevated concentrations of iodoproteins in their blood. Unfortunately, the overlap in the ranges of concentrations in normal (homozygous) and in heterozygous sheep prevented the use of this test to detect heterozygotes.

An elegant study by Hurley (1968) of genetic-nutritional interactions involving manganese was carried out on mice. Congenital ataxia occurs in offspring of mice and of many other species given a Mn-deficient diet during pregnancy. A similar condition was observed in mice with the mutant gene pallid. The genetically induced condition could, however, be prevented by Mn supplementation of the normal stock diet during pregnancy. Thus, the action of the gene could be masked by nutrition. Hurley was also able to show that the specific pathways of the two conditions differed.

\section{Genetic variation in mineral concentrations}

\section{Sheep}

Copper. Following the observation of breed differences in the incidence of swayback referred to earlier, Wiener \& Field (1966) demonstrated large differences in 
the concentrations of $\mathrm{Cu}$ in the blood of these breeds of sheep in flock A. Later work showed not only that breed differences persisted in spite of $\mathrm{Cu}$ injections and wide seasonal variation in average $\mathrm{Cu}$ concentrations of the flock but, that to a limited extent, seasonal variation was modified by genetic factors (Wiener, Field \& Wood, I969; Wiener, Field \& Jolly, 1970). Cross-bred sheep were found to have concentrations of $\mathrm{Cu}$ in their blood markedly above the mean of the parents in spite of the fact that the cross-breds had had a more nearly intermediate incidence of swayback. It was also observed that groups that had relatively high concentrations of blood $\mathrm{Cu}$ fluctuated less in concentration over the year than groups that had relatively low concentrations. Therefore, if it can be deduced that Welsh Mountain sheep, for example (a 'high' group), maintain a better homeostatic control over their $\mathrm{Cu}$ metabolism than, for example, Blackface sheep (a 'low' group), the information would point to the possibility of genetically influencing stability by choosing sheep with genetically 'high' concentrations. Payne, Dew, Manston \& Vagg (1970) also point to an inverse relationship between mean concentration and variability for concentrations of magnesium in the blood of cows.

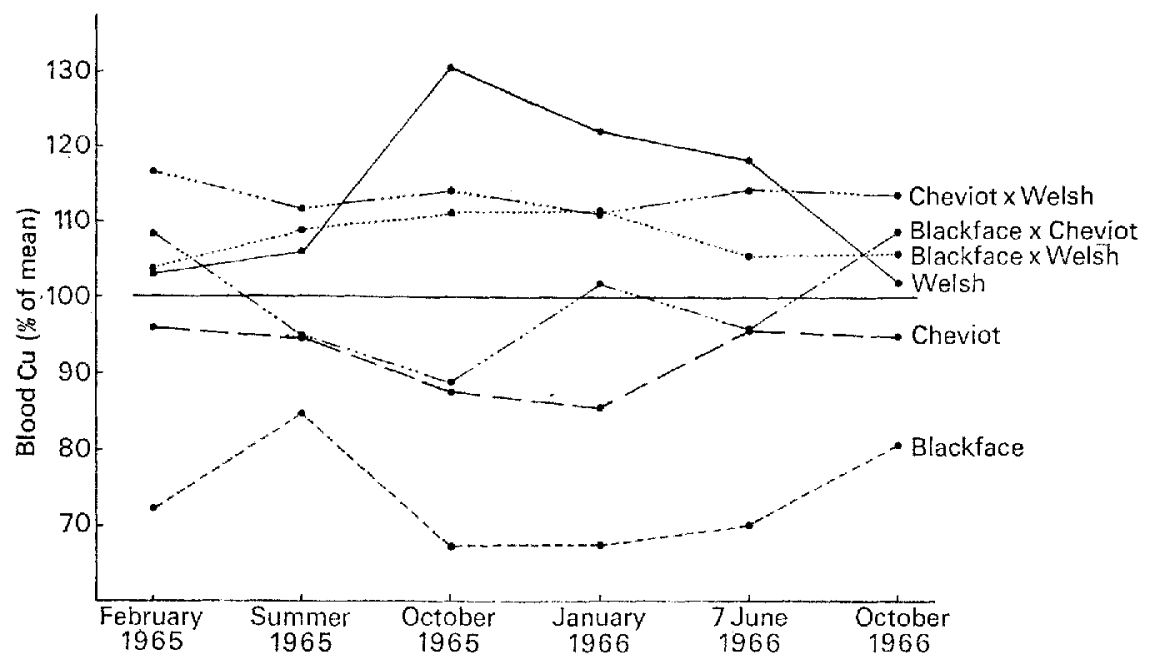

Fig. I. Concentrations of copper in the blood of ewes of six breed classes expressed as deviations from the mean of the breeds on each of six occasions, in a self-contained grassland flock (data from Wiener, Field \& Wood, 1969).

The published data from flock $A$ have been summarized in Fig. I to demonstrate the breed differences (as deviations from their mean) and their persistence over six successive bleedings when the actual, average concentrations varied from above 90 $\mu \mathrm{g} \mathrm{Cu}$ per roo $\mathrm{ml}$ blood (summer of $\mathrm{I}_{96}$ ) to below $60 \mu \mathrm{g} /$ roo ml (January, 1966). 
Fig. 2 shows the behaviour over the same i8-month period of a group of ewes which had produced swayback lambs in a previous year. This demonstrates clearly the relatively greater seasonal fluctuations of the low-Cu class - a feature less readily seen, though statistically demonstrable, for the breed classes.

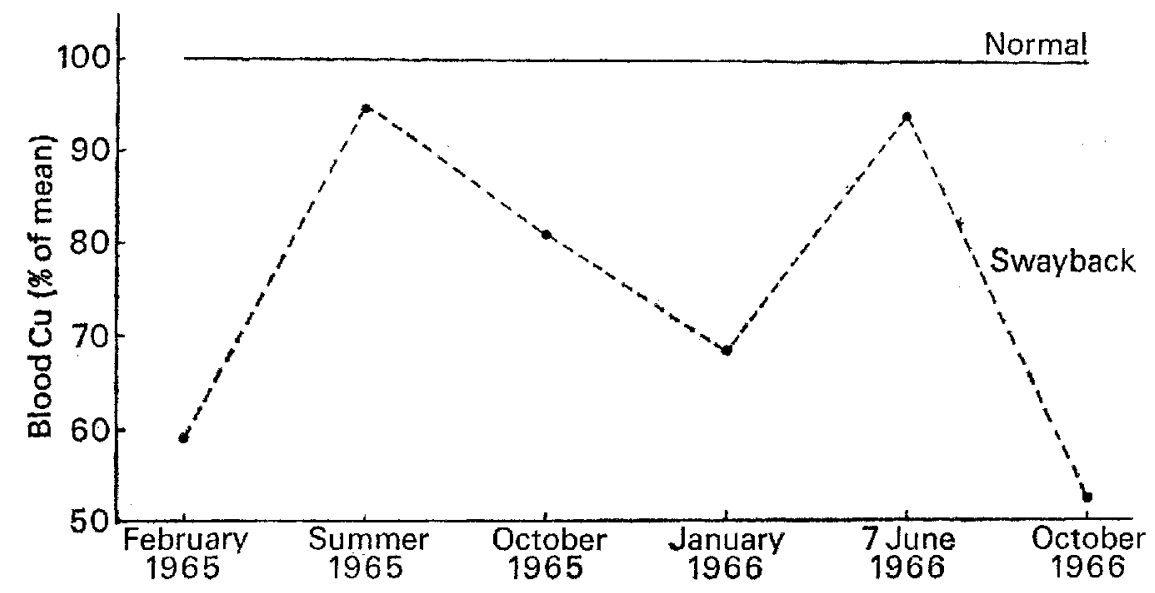

Fig. 2. Concentrations of copper in the blood of a group of twenty ewes, which had produced swayback lambs in 1964 , expressed as deviations from the concentrations in the blood of normal contemporaries in the same flock, on each of six occasions (data from Wiener, Field \& Wood, 1969).

Evidence of variation in $\mathrm{Cu}$ concentration among diverse breed crosses was also obtained from flock B (Wiener \& Field, 1971). Lamb-mother regressions calculated for data from this flock also indicated that variation in blood $\mathrm{Cu}$ concentration may be genetically variable within breeds but information on differences among sire progeny groups is still totally inadequate to allow prediction of the response of blood $\mathrm{Cu}$ to selection. That it can be affected by choice of breed and by crossbreeding seems to be far better established.

Concentrations of $\mathrm{Cu}$ in liver (Wiener \& Field, 1969a) and in brain (Wiener \& Field 1970 ) have also been examined and found to show significant breed variation. Cross-breeding appeared to affect liver values differently from blood values, thus creating genetically four classes which can be, broadly speaking, described as relatively high in both liver and blood $\mathrm{Cu}$ concentration, low in both, or relatively high in one and low in the other. This is shown in Fig. 3 by presenting the results of Wiener \& Field (1969a) as deviations from the means. It may be implied from these results that there is some measure of genetic independence of the control of concentrations in the liver and blood. Also, these results lead one to suggest that the consequences of deficiency or excess of $\mathrm{Cu}$ in the feed may differ for each class but that these might, in due course, become predictable because of the genetic basis.

Other minerals. Concentrations of calcium, magnesium, potassium, sodium and chlorine in plasma, and of phosphorus in whole blood were also examined in the two 


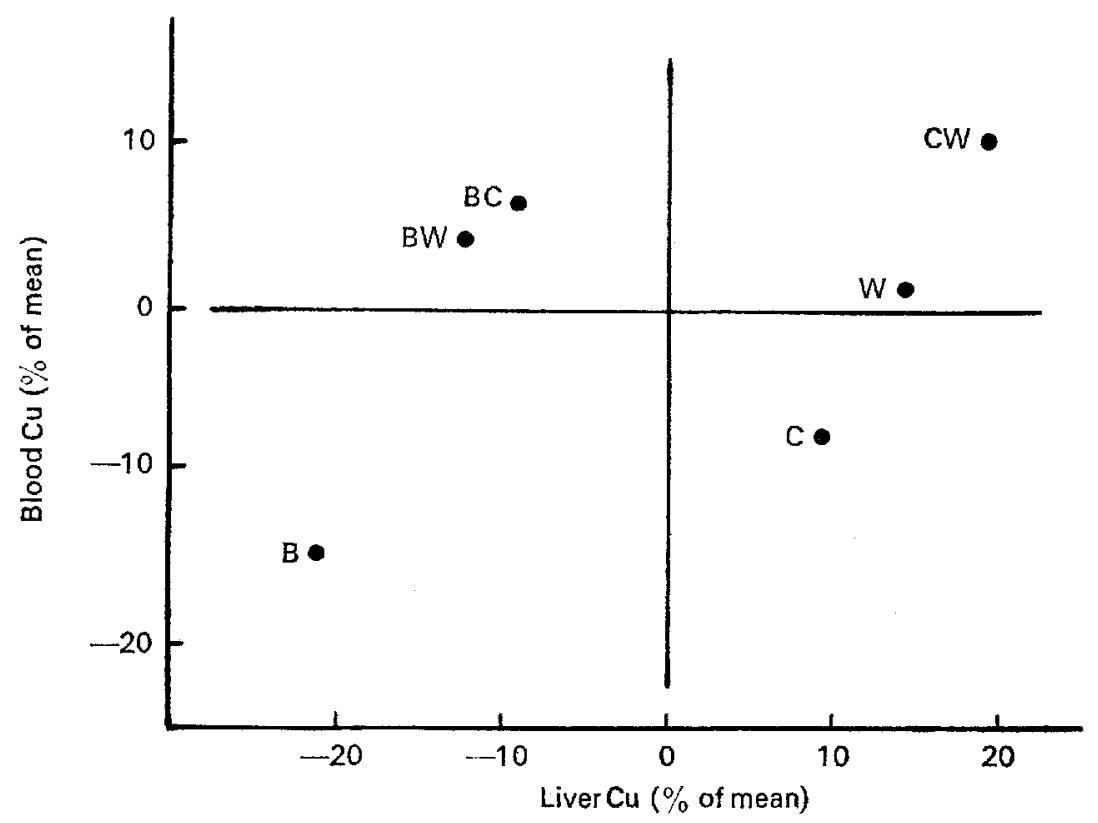

Fig. 3. Breed means for the concentrations of copper in the liver and blood of sixty-eight, 5-year-old ewes expressed as deviations from the mean of the breeds (data from Wiener \& Field, 1969a). B, Blackface; C, Cheviot; W, Welsh; BC, Blackface $\times$ Cheviot; BW, Blackface $\times$ Welsh; CW, Cheviot $\times$ Welsh.

flocks (A and B). Based on a single bleeding, the results showed significant breed variation for $\mathrm{Ca}, \mathrm{P}, \mathrm{Mg}$ and $\mathrm{Cl}$ although the contribution of breed (or cross-breed) to the total variation was less than $10 \%$ except for $\mathrm{Mg}$ where it was $20 \%$ (Field, Wiener \& Wood, 1969; Wiener \& Field, 1971).

One of the most interesting facts to emerge was that eighteen of the twenty sheep (in flock A) with $\mathrm{Mg}$ concentrations below I $\mathrm{mg} / \mathrm{I}$ ) $\mathrm{ml}$ blood plasma were Cheviots or Cheviot crosses. Ritchie \& Hemingway (1963) reported that Cheviot sheep had lower $\mathrm{Ca}$ and $\mathrm{Mg}$ values than Cheviot $\times$ Border Leicester crosses, and Sykes, Field \& Slee (1969) observed a difference in Ca concentrations between Southdown and Welsh Mountain sheep. Differences among sires within breed (Wiener \& Field, 1971) were not found to be statistically significant but the number of such comparisons and the relatively small number of progeny for each sire made this not surprising, unless genetic effects were overwhelmingly large in relation to variation from other causes.

Several breeds were involved in experiments with housed sheep on dry-lot reported by Long, Ullrey, Miller, Vincent \& Zutant (1965). They observed no consistent breed differences in the concentrations of serum $\mathrm{Ca}, \mathrm{P}, \mathrm{Mg}, \mathrm{Na}$ and $\mathrm{K}$. Becker $\&$ Smith (1950) found no breed difference in plasma $\mathrm{Ca}$ and $\mathrm{P}$ among a small group of sheep also housed. Eagleton, Hall \& Russell (1970) have recently reported an 
influence of breed and $K a$ genotype on $\mathrm{K}$ concentrations in plasma of grazing sheep.

A population appropriate for a study of genetic correlations among the concentrations of minerals in blood has not yet been sampled but, superficially, the relationships involving breeds (Wiener \& Field, $1969 b$, 197 I) suggest that genetic changes in the concentration of one mineral may well be accompanied by changes in the concentration of others. 'The point is further illustrated by the marked genetic relationship of $\mathrm{K}$ and $\mathrm{Na}$ in whole blood where a gene for high and low $\mathrm{K}$ concentration has been demonstrated (Evans \& King, 1955).

\section{Cattle}

Almost all the evidence capable of yielding genetic information on aspects of mineral metabolism is derived from experiments involving monozygotic twins. If monozygotic twins alone are used in an experiment, the importance of the genetic variation as a proportion of the total (heritability) is nearly always overestimated. The estimate of genetic variation is improved if contemporary pairs of animals of lesser relationship (e.g. dizygotic twins, half-sisters, etc.) are used along with monozygotic twins. Both genetic and environmental components of variation can then be estimated from within pairs, (see King \& Donald, I955). An experiment of this structure has been used for a study of mineral concentrations in blood and some preliminary results are presented.

Blood. Samples were obtained at a single bleeding in November 1969 for five pairs of monozygotic twins, nine pairs of dizygotic twins, twenty pairs of half-sisters and eleven pairs of unrelated animals, all female and with pair members at approximately the same stage of pregnancy and lactation. Pair members of the two non-twin classes were of the same breed, born within a few days of each other and treated alike - for all essential purposes as twins. The animals were part of a continuing uniformity trial first described by Donald (1953). At the time of bleeding all the animals were housed and individually fed.

The genetic analysis on within-pair variation was based on the simplest assumption that all variation could be attributed to a single environmental and a single genetic component, the proportion of the genetic variation depending on the relationship of the pair members. Variation between pairs was not considered. A leastsquares solution ensured that the environmental component was not deduced from monozygotic twins alone. The simple assumptions fitted the data well and the results are shown in Table $\mathrm{I}$ with the genetic variation expressed as a percentage of the total. For $\mathrm{K}$ concentration the results were absurd (partial haemolysis in a few samples came to be suspected afterwards) and have been interpreted as indicating zero genetic variation. The estimate of genetic variation for $\mathrm{P}$ concentration is little greater than its standard error, but for the other minerals the results suggest a moderately high heritability. 
Table 1. Estimates of genetic variation expressed as a percentage of total variation for the concentrations of various minerals and of glucose in the blood plasma* of cattle from a single breeding $\dagger$

$\begin{array}{lccccccc} & \mathrm{Cu} & \mathrm{Ca} & \mathrm{P} & \mathrm{Mg} & \mathrm{Kf} & \mathrm{Na} & \text { Glucose } \\ \text { Percentage } & 63 & 82 & 46 & 58 & \circ & 8 \mathrm{I} & 64 \\ \text { Approximate standard error } & 27 & \mathrm{I} 3 & 39 & 3 \mathrm{I} & - & \mathrm{I4} & 26\end{array}$

"Whole blood for $P$.

†Based on five pairs of monozygotic twins, nine pairs of dizygotic twins, twenty pairs of contemporary half-sisters and eleven pairs of contemporary unrelated females.

$\ddagger$ Estimates were negative with high $\mathrm{SE}$ - interpreted as implying zero genetic variation.

Indications from other sources for genetic variation in mineral concentrations are as follows.

E. A. McPherson, H. S. McTaggart, St C. S. Taylor and G. B. Young (unpublished) have shown genetic variation in $\mathrm{Ca}, \mathrm{Mg}$ and $\mathrm{P}$ concentrations in an experiment with contemporary monozygotic and dizygotic twins on varying planes of nutrition.

Hansson (1948) and Hancock (1952) using monozygotic twins only (three pairs and nineteen pairs respectively) in greatly differing experimental situations agree, however, that variation between pairs was markedly greater than that within pairs for the concentrations of $\mathrm{Ca}$ and $\mathrm{P}$. The same finding was made for $\mathrm{Mg}$ concentration studied by Hancock.

Payne et al. (1970), in the only non-twin work relevant here, have provided initial results on average $\mathrm{Mg}$ concentrations from one herd based on variable numbers of offspring of ten different bulls (from seven to twenty-three progeny per bull). The values for sire progeny groups ranged from $2 \cdot 2$ to $2.9(\mathrm{mg} / 100 \mathrm{ml}$ plasma) but no indication was given whether the variation among the sires was statistically significant or, if it were, whether it could be attributed to genetic differences. From other evidence on variation in blood $\mathrm{Mg}$ values and the numbers used, it seems unlikely that any but the extreme average values in this sample would differ significantly. Clearly, however, evidence of this type from larger numbers and a wider range of conditions will help to decide whether genetic variation for specific traits can be detected under field conditions and whether, when defined in this simple form, it can be related to metabolic disorders and productivity.

Milk. Using monozygotic twins only, Hansson (1948) examined $\mathrm{Ca}$ and $\mathrm{P}$ concentration in three pairs; Comberg, Andreae \& Meyer (I962-I963), the concentrations of $\mathrm{Ca}, \mathrm{P}, \mathrm{Mg}, \mathrm{Na}$ and $\mathrm{K}$ in six pairs; and Field ( $1970 a$, r970b), the concentration of $\mathrm{Ca}, \mathrm{Mg}$ and $\mathrm{K}$ in three pairs. Again, in spite of the very different conditions of the three experiments, the results agree in showing much greater variation between than within pairs, implying a hereditary basis for the variation.

Excreta. Field \& Suttle (1970) reported results from an experiment in which 
dietary $\mathrm{Mg}$ and $\mathrm{K}$ were varied to study mineral interrelationships. Three pairs of monozygotic twins were used, but care was taken to ensure that the different pairs were of the same breed, age, physiological state and of similar weight. Values for urinary and faecal excretion of $\mathrm{Mg}, \mathrm{Ca}, \mathrm{P}, \mathrm{Na}$, and $\mathrm{K}$ showed that, in the urine, between-pair variation exceeded within-pair variation for $\mathrm{Mg}, \mathrm{Ca}$ and, most markedly, for $\mathrm{P}$; and in the faeces for $\mathrm{Na}$ and $\mathrm{K}$. Since dietary $\mathrm{Na}$ and $\mathrm{K}$ are assumed to be completely available to the animal (Agricultural Research Council, I965), the faecal losses can be equated with endogenous losses, and the results from the twins as evidence of genetic variation of $\mathrm{Na}$ and $\mathrm{K}$ in such losses.

The same study provided an indirect measure of the utilization of dietary Mg by the cows. The mean values for the three twin pairs were $22.8,7.4$ and $18.6 \%$ and differences within pairs were small.

\section{Discussion}

The evidence suggests that genetic variation exists both in the incidence of some disorders associated with mineral metabolism and in the concentrations of minerals in animal tissues and fluids. As yet, only a few of the minerals and even fewer of the trace elements essential to life have been investigated from this point of view. It is clear, however, that the large part of the variation among individual animals which was hitherto unaccounted for, should not be attributed wholly to chance.

Most of the reports on mineral concentrations in blood, with the possible exception of some of those on $\mathrm{Cu}$, are concerned with variation in the apparently normal range (Underwood, 1962, 1966), although 'normality' itself is not necessarily the same for animals or for groups of animals that are different genetically. In many of the instances within this range, the genetic proportion of the total variation was found to be quite small. It does not follow, however, that the genetic fraction is negligible. Many of the other recognizable sources of variation - for example, the age or physiological state of an animal - are unalterable or cannot be modified in practice, and still other variation in mineral concentration has, as yet, completely unknown causes.

Underwood (1966) has stated that blood, in some aspect of its composition, invariably reflects the mineral status of an animal and often provides an early warning of deficiency, excess or imbalance. The question, therefore, arises whether genetically influenced variation in mineral status, as reflected by blood (or other fluids or tissues), is associated with genetically different needs of the animal. Does a breed with, for example, a genetically low average blood $\mathrm{Cu}$ concentration have a different requirement for dietary $\mathrm{Cu}$ from a breed with a genetically high average concentration? Is the one more prone to disorder than the other? For swayback there was clearly such an association but, more surprisingly, the evidence suggested that the concentration of $\mathrm{Cu}$ below which swayback occurred was itself influenced by heredity (Wiener, Field \& Wood, I969).

If genetic variation in requirements can be established, the nutritionist and veterinarian will have a more accurate means of assessing and of meeting require- 
ments under those circumstances where the environment can be easily manipulated.

In this context it is interesting to note that Goldring, Schaible \& Davidson (I940) reported a breed difference in the Mn requirement of laying hens and that Schwarz (1970) has recorded differences between genetically different strains of rats in the quantities of Se needed for a $50 \%$ protection against dietary liver necrosis.

Under other circumstances where the environment cannot be readily changed, it may be more appropriate to change the genotype. This could apply in vast areas of natural grazing across the world where mineral deficiencies and excesses would be very costly to rectify. It could also apply under intensive husbandry conditions where the provision of the appropriate feed may be prohibitively expensive. This might be argued, for example, in the provision of feeds sufficiently low in $\mathrm{Cu}$ to avoid poisoning in housed sheep and, in particular, those kept for breeding.

Another situation which might be met by genetic means is in producing animals with relatively stable concentrations of minerals in, for example, blood. This may be desirable if it reflects a lesser sensitivity (better physiological homeostasis) of the animal to adverse changes in the availability of, or requirements for, a mineral and if it involves factors which may not be readily controllable by husbandry. Only a little indirect evidence is available, as yet, of a genetic component of stability in $\mathrm{Cu}$ concentration. But a clue that a breeding policy aimed at achieving stability might be practical comes from the reported inverse association between average concentration and variability for $\mathrm{Cu}$ and $\mathrm{Mg}$.

An important question relates to the magnitude of genotype-environment interactions which may be expected to occur. Is genetic variation in mineral status equally manifested under different environmental conditions and levels of nutrition? There is no direct experimental evidence on this point, and the indirect evidence is scant and equivocal. The absence of breed variation in an experiment with housed sheep fed on dry-lot in the USA, might be contrasted with the occurrence of breed variation for grazing sheep in experiments here and claimed as evidence for interaction. Equally, the different results may derive from the different breeds used. The marked breed differences for $\mathrm{Cu}$ concentration reported by Wiener and Field were almost certainly more important as a source of variation at all times of year than the reported interactions with season. But if the $\mathrm{Cu}$ results are thought to be specific to a farm situation with relative $\mathrm{Cu}$ deficiency there is no obvious evidence of nutritional deficiency of the other minerals for which genetic variation in concentration has also been reported.

The differences among minerals in their biological function, in their availability and in the way they are handled by the animal makes it contentious to generalize from one mineral to another. The present discussion should therefore be regarded mainly as an exploration of possibilities. The implications of genetic variation may well differ for different minerals.

The recognition of genetic variation in mineral metabolism, for which there is now some evidence for nearly every mineral where it has been sought, does not create any new problem for the nutritionist which did not already exist, but it is likely to provide an additional opportunity, in at least some circumstances, for 
avoiding disorders due to mineral deficiency, excess or imbalance and perhaps for helping to optimize animal performance.

We are indebted to Mr W. S. Russell for the statistical analysis of the data on cattle blood leading to the results shown in Table $\mathrm{r}$.

\section{REFERENCES}

Agricultural Research Council (r965). The Nutrient Requirements of Farm Livestock. No. 2. Ruminants. London: Agricultural Research Council.

Becker, D. E. \& Smith, S. E. (1950). Cornell Vet. 40, 350.

Comberg, G., Andreae, U. \& Meyer, H. (1962-1963). Z. Tierzücht. ZuchtBiol. 78, 5.

Donald, H. P. (1953). F. Dairy Res. 20, 355.

Eagleton, G. H., Hall, J. G. \& Russell, W. S. (1970). Anim. Blood Groups Biochem. Genet. 1, 135.

Evans, J. V. \& King, J. W. B. (1955). Nature, Lond. 176, 171.

Falconer, I. R. (1965). Nature, Lond. 205, 978.

Field, A. C. (1970a). Br. Y. Nutr. 24, 71 .

Field, A. C. $(197 \circ b)$. Br. 7. Nutr. 24, 85 .

Field, A. C. \& Suttle, N. F. (1970). Proc. Nutr. Soc. 29, 34A.

Field, A. C., Wiener, G. \& Wood, J. (1969). F. agric. Sci., Camb. 73, 267.

Goldring, W. V., Schaible, P. J. \& Davidson, J. A. (1940). Poult. Sci. 19, 263.

Hancock, J. (1952). N.Z. fl Sci. Technol. (A) 34, I31.

Hansson, A. (1948). Acta agric. suec. 3, 59.

Hurley, L. S. (1968). In Proceedings of the Second Annual Conference on Trace Substances in Environmental Health p. 4I [D. D. Hemphill, editor]. University of Missouri.

King, J. W. B. \& Donald, H. P. (1955). F. Dairy Res. 22, I.

Leech, F. B., Davis, M. E., Macrae, W. D. \& Withers, F. W. (1960). Disease, Wastage and Husbandry in the British Dairy Herd. London: H.M. Stationery Office.

Long, C. H., Ullrey, D. E., Miller, E. R., Vincent, B. H., \& Zutant, C. L. (1965). F. Anim. Sci. 24 , I45.

Marston, H. R. (1950). In Copper Metabolism, Discussion, p. 272, 3 r 3 [W. D. McElroy and B. Glass,
[W. editors]. Baltimore, Md: John Hopkins Press.

Mayo, G. M. E. \& Mulhearn, C. J. (I969). Aust. f. agric. Res. 20, 533.

Meyer, H. (1968). Vererburg und Krankheit bei Haustieren. Hannover: Verlag M. \& H. Schaper.

Payne, J. M., Dew, S. M, Manston, R. \& Vagg, M. J. (1970). In Physiology of Digestion and Metabolism in the Ruminant p. $5^{84}$ [A. T. Phillipson, editor]. Newcastle upon Tyne: Oriel Press Ltd.

Rac, R., Hill, G. N., Pain, R. W. \& Mulhearn, C. J. (1968). Res, vet. Sci. 9, 209.

Ritchie, N. S. \& Hemingway, R. G. (1963). Y. agric. Sci., Camb. 61, 41 r.

Schwarz, K. (1970). In Trace Element Metabolism in Animals p. 525 [C. F. Mills, editor]. Edinburgh: E. \& S. Livingstone.

Suttle, N. F. \& Field, A. C. (1969). F. comp. Path. Ther. 79, 453.

Sykes, A. R., Field, A. C. \& Slee, J. (1969). Anim. Prod. Ir, 9r.

Underwood, E. J. (1962). Trace Elements in Human and Animal Nutrition 2 nd ed. London and New York: Academic Press.

Underwood, E. J. (1966). The Mineral Nutrition of Livestock. Farnham Royal: Commonwealth Agricultural Bureaux.

Wiener, G. (r966). F. comp. Path. Ther. 76, 435.

Wiener, G. (I97I). Y comp. Path. Ther. (In the Press.)

Wiener, G. \& Field, A. C. (1966). Nature, Lond. 209, 835 .

Wiener, G. \& Field, A. C. (1969a). 7. comp. Path. Ther. 79, 7 .

Wiener, G. \& Field, A. C. (1969b). F. agric. Sci., Camb. 73, 275.

Wiener, G. \& Field, A. C. (r970). In Trace Element Metabolism in Animals p. 92 [C. F. Mills,
[ editor]. Edinburgh: E. \& S. Livingstone.

Wiener, G. \& Field, A. C. (I971). F, agric. Sci., Camb. (In the Press.)

Wiener, G., Field, A. C., \& Jolly, G. M. (1970). F. agric. Sci., Camb. 75, 489.

Wiener, G., Field, A. C. \& Wood, J. (1969). F. agric. Sci., Camb. 72, 93.

Wiener, G. \& Macleod, N. S. M. (1970). Vet. Rec. 86, 740.

Wiener, G. \& Sampford, M. R. (1969). 9. agric. Sci., Camb. 73, 25. 